\title{
Implementation of colonoscopy quality monitoring in a Belgian university hospital with integrated computer-based extraction of adenoma detection rate
}

다(1)이우

\author{
Authors \\ Institutions \\ 1 Department of Gastroenterology, Hepatopancreatology \\ and Digestive Oncology, Erasme Hospital, Université \\ Libre de Bruxelles (ULB), Brussels, Belgium \\ 2 IT Department, Medicotechnical Team, Erasme \\ Hospital, Université Libre de Bruxelles (ULB), Brussels, \\ Belgium \\ 3 Department of Pathology, Jules Bordet Institute, \\ Université Libre de Bruxelles (ULB), Brussels, Belgium \\ 4 Department of Hepato-Gastroenterology, Saint-Pierre \\ Hospital, Université Libre de Bruxelles (ULB), Brussels, \\ Belgium
}

Sohaib Ouazzani ${ }^{1}$, Arnaud Lemmers ${ }^{1}$, Federico Martinez ${ }^{2}$, Raphael Kindt ${ }^{2}$, Olivier Le Moine ${ }^{1}$, Myriam Delhaye ${ }^{1}$, Marianna Arvanitakis ${ }^{1}$, Pieter Demetter ${ }^{3}$, Jacques Devière ${ }^{1}$, Pierre Eisendrath ${ }^{1,4}$

submitted 12.9.2019

accepted after revision 30.12.2019

\author{
Bibliography \\ Endoscopy International Open 2021; 09: E197-E202 \\ DOI 10.1055/a-1326-1179 \\ ISSN 2364-3722 \\ (C) 2021. The Author(s) \\ This is an open access article published by Thieme under the terms of the Creative \\ Commons Attribution-NonDerivative-NonCommercial License, permitting copying \\ and reproduction so long as the original work is given appropriate credit. Contents \\ may not be used for commecial purposes, or adapted, remixed, transformed or \\ built upon. (https://creativecommons.org/licenses/by-nc-nd/4.0/) \\ Georg Thieme Verlag KG, Rüdigerstraße 14, \\ 70469 Stuttgart, Germany \\ Corresponding author \\ Sohaib Ouazzani, Hopital Erasme - GASTROENTEROLOGY, \\ Route de Lennik 808 Bruxelles 1070, Belgium \\ Fax: +325553712 \\ sohaib.ouazzani@ulb.be
}

\section{ABSTRACT}

Background and study aims Quality in colonoscopy has been promoted in last decade with definition of different quality indicators (QI) as benchmarks. Currently, automatized monitoring systems are lacking, especially for merging pathologic and endoscopic data, which limits quality monitoring implementation in daily practice. We describe an adapted endoscopy reporting system that allows continuous QI recording, with automatic pathological data inclusion.

Material and methods We locally adapted a reporting system for colonoscopy by adding and structuring in a dedicated tab selected key QI. Endoscopic data from a reporting system and pathological results were extracted and merged in a separate database. During the initial period of use, performing physicians were encouraged to complete the dedicated tab on a voluntary basis. In a second stage, completing of the tab was made mandatory. The completeness of QI recording was evaluated across both periods. Performance measures for all endoscopists were compared to global results for the department and published targets.

Results During the second semester of 2017, a total of 1827 colonoscopies were performed with a QI tab completed in $100 \%$ of cases. Among key QI, the cecal intubation rate was $93.8 \%$, the rate of colonoscopies with adequate preparation was $90.7 \%$, and the adenoma detection rate was $29.8 \%$ considering all colonoscopies, irrespective of indication; $28.8 \%$ considering screening procedures; and $36.6 \%$ in colonoscopies performed in people older than age 50 years.

Conclusion This study shows that quality monitoring for colonoscopy can be easily implemented with limited human resources by adapting a reporting system and linking it to a pathology database.

\section{Introduction}

Colonoscopy is essential for diagnosis and treatment of colonic diseases and plays a key role in colorectal cancer (CRC) screening, resulting in effective reduction of incidence and related mortality [1,2]. However, poor-quality colonoscopy is associated with missed lesions, contributing to increased rates of interval cancers [3]. This has led to many recent publications on quality in colonoscopy and attempts to implement quality monitoring in endoscopy units worldwide. Various national 
and international professional societies have defined several QI to measure the quality of practice and compare local performance and benchmarks. This offers the possibility, by feedback to improve colonoscopy quality [4-6] and finally patient outcomes [7].

Initiation of continuous quality monitoring suffers from constraints related to both technical and human resources. Recently, the European Society of Gastrointestinal Endoscopy (ESGE) published a list of requirements and standards for endoscopy reporting systems to ensure adequate quality assessment and improvement [8]. They recommend restricted use of free text and also structured and standardized data entry. They also discourage separation of databases and support automatic linkage between an endoscopy reporting system and other databases, with inclusion of information on histopathology of detected lesions. The drawback of the adenoma detection rate (ADR) monitoring, considered as one of the main QI in lower gastrointestinal endoscopy [9], is the need to obtain this automatic linkage to avoid manual data entry of pathological data, which is a clear human and economic limit in QI monitoring implementation. This critical point has been considered as an urgent need in colonoscopy quality monitoring [10]. However, until now, there have been no published data on implementation of a system in endoscopy units that automatically links endoscopy report results and pathologic data from resected polyps to enhance quality monitoring in colonoscopy.

In the present study, we report on the feasibility of implementing a colonoscopy QI recording system by automatically extracting data from two separate databases to obtain endoscopic and pathological information.

\section{Material and methods}

\section{Electronic reporting system use and adaptation}

During 2016 and 2017, the reporting system used in our endoscopy unit was the version 13.5 Endobase software system (Olympus, Winter \& Ibe $\mathrm{GmbH}$, Hamburg, Germany). It was configured to include patient's general characteristics, technical information, and results from the procedure, incorporated by the endoscopist. The pathology software used was the Diamic software system, version 8 (Infologic-santé, Valence, France).

Before the procedure, the software automatically enters information on patient identification and the type of scope (with serial number) used, whereas information on the physicians and staff involved were recorded manually. During the endoscopy procedure, photographs of anatomic landmarks and lesions are taken and saved in the software. After completion of the colonoscopy, endoscopists choose photographs to include in the final report. Then they add in appropriate tabs information on the indication of colonoscopy, type of sedation, and other medication administered during colonoscopy, type and quality of bowel preparation, normal and pathological findings, procedure indicators (PI), biopsies, endoscopic treatments, conclusions, and clinical advice. Data are systematically entered by selecting options from a drop-down menu, with predefined and structured terminology, limiting free text to a minimum. In the case of polyps, different structured data are added in dedicated tabs to record their size, morphology (using different classifications as Paris, NICE, laterally spreading tumor type), and also information about the polypectomy technique and results. Once all description information has been entered, a written report is generated and displayed in a word processor to allow for possible modifications and selected endoscopy photographs.

To ensure continuous measurement of colonoscopy performance, this commercially available reporting system was locally adapted by adding a dedicated tab, named quality monitoring, with a specific tab for each selected QI. Some are automatically added from previously entered items (i. e., type of sedation, level of progression and quality of bowel preparation); others are added at the end of the procedure by the endoscopist (indication for colonoscopy and number of polyp(s) resected).

\section{Quality indicators}

Based on the current literature and international guidelines, we selected several endoscopy QI that are recognized to be key performance measures, associated with clinically relevant outcomes, and available in routine clinical practice. They include ADR (i. e. the rate of colonoscopies with at least one adenoma identified), cecal intubation rate (CIR) (i.e. the percentage of complete colonoscopies, defined as reaching and visualizing the whole cecum and its landmarks) and the proportion of colonoscopies with adequate bowel preparation. We used the Boston Bowel Preparation Scale (BBPS) to evaluate the quality of preparation, with adequate preparation defined by a score better than $5[4,11]$. We also included the polyp detection rate (PDR) (i.e. the rate of colonoscopies in which at least one polyp was identified).

The ADR was broken down into several indications. As recommended [4], we measured ADR for all patients aged 50 years or older (i.e. ADR 50). We also calculated the ADR for screening colonoscopies performed in asymptomatic patients with average risk for colorectal cancer (i.e. ADR screening) and also in all colonoscopies irrespective of the indication for the procedure (including screening colonoscopy, follow-up colonoscopy, and diagnostic and therapeutic colonoscopy, i.e. ADR total).

\section{Datas extraction and analysis}

On a regular basis or on request, PI encoded during each colonoscopy are automatically extracted from the Endobase software to a first database (the endoscopic database) ( $\triangleright$ Table 1 ). In parallel, pathology results from resected polyps are extracted from Diamic software in a second database (the pathology database) ( $>$ Table 2 ) through the use of SNOMED CT codes to recognize each type of lesion and its site. A list of "trigger" SNOMED CT codes corresponding to different adenomatous lesions were chosen after discussion with our pathology team ( $\triangleright$ Table 3 ). When one of these codes is selected by the pathologist, they automatically trigger a positive result on the corresponding colonoscopy. Only the codes corresponding to an adenomatous lesion can trigger this result. Structured query language (SQL) is used to extract data from both databases. Each PI extracted 
$\checkmark$ Table 1 Example of a procedure in the endoscopic database.

\begin{tabular}{|l|l|l|l|l|l|l|}
\hline Patient ID & Age & Procedure Date & Procedure Type & Endoscopist ID & PI type & PI result \\
\hline Patient 1 & 51 & $\mathrm{dd} / \mathrm{mm} / \mathrm{yy}$ & Colonoscopy & 17 & Type of sedation & Propofol sedation \\
\hline Patient 1 & 51 & $\mathrm{dd} / \mathrm{mm} / \mathrm{yy}$ & Colonoscopy & 17 & Level of progression & Cecum \\
\hline Patient 1 & 51 & $\mathrm{dd} / \mathrm{mm} / \mathrm{yy}$ & Colonoscopy & 17 & Indication & Screening (average risk) \\
\hline Patient 1 & 51 & $\mathrm{dd} / \mathrm{mm} / \mathrm{yy}$ & Colonoscopy & 17 & Number of polyp resected & 2 \\
\hline Patient 1 & 51 & $\mathrm{dd} / \mathrm{mm} / \mathrm{yy}$ & Colonoscopy & 17 & Preparation & 9 \\
\hline Patient 1 & 51 & $\mathrm{dd} / \mathrm{mm} / \mathrm{yy}$ & Colonoscopy & 17 & Planned procedure & Total Colonoscopy \\
\hline
\end{tabular}

- Table 2 Example of a pathology result (corresponding to $\$ Table 1 ) in the pathology database.

\begin{tabular}{|c|c|c|c|}
\hline Patient ID & Reception date & Morphology code & Site code \\
\hline Patient 1 & $\mathrm{dd} / \mathrm{mm} / \mathrm{yy}$ & $\mathrm{M}-74002$ & $\mathrm{~T}-59300$ \\
\hline Patient 1 & $\mathrm{dd} / \mathrm{mm} / \mathrm{yy}$ & $\mathrm{M}-74002$ & $\mathrm{~T}-59300$ \\
\hline
\end{tabular}

- Table 3 List of "trigger" SNOMED CT codes.

\begin{tabular}{|l|l|}
\hline Morphology code SNOMED CT & Corresponding pathology \\
\hline M-74000 & Dysplasia \\
\hline M-74001 & Mild dysplasia \\
\hline M-74002 & Moderate dysplasia \\
\hline M-74003 & Severe dysplasia \\
\hline M-81403 & Adenocarcinoma \\
\hline M-84803 & Colloid adenocarcinoma \\
\hline M-82633 & Papillary adenocarcinoma \\
\hline
\end{tabular}

from the databases is used to calculate a corresponding QI. To automatically calculate the ADR, merging of two databases is necessary and performed based on the patient identifier (unique for each patient and used by all software in our hospital) and the date of the procedure. Merger of the two databases creates a third database ( $\triangleright$ Table 4 ), from which all QI (including ADR) are automatically calculated for each physician and for the whole unit. All of these steps are summarized in $>$ Fig. 1 .

To avoid mistakes during database merger, two internal quality controls were performed by a staff member. For each control, the staff member reviewed hundred successive pathological results and compared them with the results obtained by the automatic extraction and calculated a rate of concordance, which was $100 \%$.

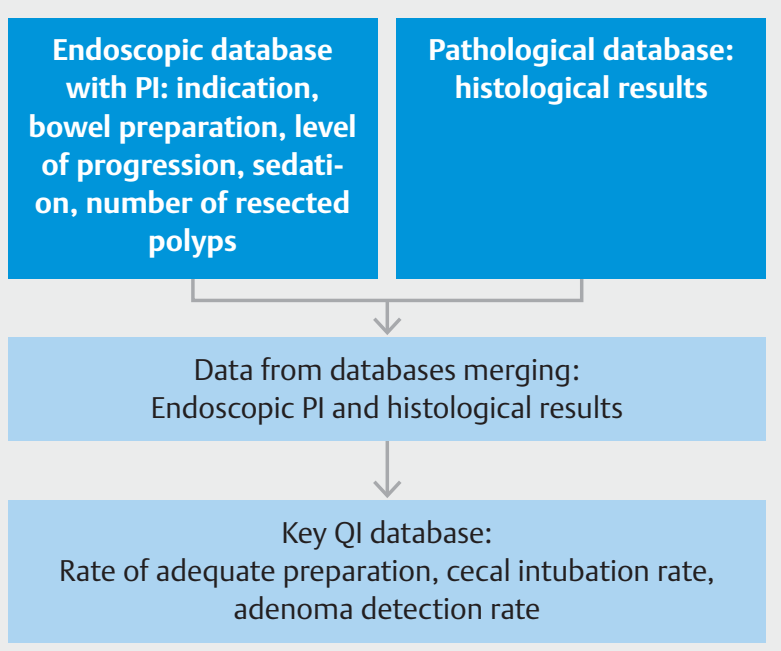

- Fig. 1 Data extraction and merging of databases.

\section{Training (second semester of 2016)}

Before the initiation of continuous quality recording, the project was presented to the endoscopic unit, with staff awareness about the quality in endoscopy implementation program and the importance of its recording. During the final months of 2016, endoscopists were encouraged to voluntarily insert information into the dedicated tab and the completeness of QI recording was evaluated. An exam was considered fully filled if all of the PI tabs were filled.

During 2017, the filling was turned to be mandatory so that the report cannot be finalized before the filling of each tab. Performance measures for all endoscopists were compared with global results for our department and with published targets.

- Table4 Example of result from merging of databases.

\begin{tabular}{|l|l|l|l|l|l|l|}
\hline Date of procedure & Patient ID & Polyp & Number of polyp(s) & Total Colonoscopy & Indication & Morphology Code \\
\hline $\mathrm{dd} / \mathrm{mm} / \mathrm{yy}$ & Patient 1 & $\mathrm{Y}$ & 2 & $\mathrm{Y}$ & $\mathrm{Y}$ & $\mathrm{M}-74002$ \\
\hline
\end{tabular}


- Table 5 Quality analysis of six endoscopists (July to December 2017).

\begin{tabular}{|c|c|c|c|c|c|c|c|}
\hline $\begin{array}{l}\text { Endoscopist (no. of } \\
\text { colonoscopies) }\end{array}$ & $\begin{array}{l}\text { Average } \\
\text { BBPS }\end{array}$ & APR (\%) & CIR (\%) & PDR (\%) & $\begin{array}{l}\text { ADR } 50 \\
\text { (\%) }\end{array}$ & $\begin{array}{l}\text { ADR screening } \\
\text { (\%) }\end{array}$ & $\begin{array}{l}\text { ADR (all colonos- } \\
\text { copies) (\%) }\end{array}$ \\
\hline Endoscopist 1 (63) & 8.2 & 96.8 & 90.5 & 68.3 & 66 & 50 & 60.3 \\
\hline Endoscopist 2 (172) & 7.1 & 90.1 & 94.2 & 28.5 & 22.3 & 28.6 & 18 \\
\hline Endoscopist 3 (77) & 7.6 & 96.1 & 100 & 51.9 & 42.2 & 41.7 & 35.1 \\
\hline Endoscopist 4 (38) & 7.6 & 94.7 & 100 & 39.5 & 25 & 33.3 & 23.7 \\
\hline Endoscopist 5 (56) & 7.6 & 92.9 & 94.6 & 39.3 & 41.3 & 25 & 33.9 \\
\hline Endoscopist 6 (110) & 6.7 & 89.1 & 90.9 & 17.3 & 21.9 & 12.5 & 12.7 \\
\hline
\end{tabular}

\section{Results}

A total of 3762 colonoscopies were performed in Erasme Hospital, a tertiary university hospital. The medical team is composed of 22 gastroenterologists who regularly perform colonoscopies (more than 40 procedures a year [12]). There is no organized colonoscopy-based screening program in our country, and in our institution, the majority (59\%) of colonoscopies are diagnostic procedures, performed for clinical, biological or radiological abnormalities. The others are performed for "opportunity" CCR screening and follow-up (38\%) or for scheduled therapeutic procedures (3\%). The endoscopic profile of each endoscopist varies, depending on his clinical activity.

During the quality monitoring training period of 6 months (July 1, 2016 to December 31, 2016), 1935 colonoscopies were performed with a QI tab fully completed in $63.1 \%$ of cases. Of the QI data, automatically extracted QI (bowel preparationquality and type of sedation) were entered into the specific QI tab in $99.9 \%$ and $97.5 \%$ of cases, respectively, whereas manually filled QI data (progression, number of polyps resected, and indication) were entered into the specific tab in $79.6 \%, 76.6 \%$, and $76.3 \%$ of cases, respectively.

After this training period, completion of the tab became mandatory and 1827 colonoscopies were performed from July 1, 2017 to December 31, 2017. The QI tab was fully filled for all colonoscopies. For the entire 6 -month period, the following results were revealed by the QI monitoring.

The majority of colonoscopies were performed under propofol sedation (93.8\%). The global mean BBPS was 7.4, with $90.7 \%$ of colonoscopies performed with adequate preparation. That was more the case for outpatient $(92.2 \%)$ than for inpatient $(87.2 \%)$ colonoscopies $(P=0.005)$. The procedure was complete, with reach to and visualization of the whole cecum and its landmarks, in $93.8 \%$ of all colonoscopies and $96.5 \%$ of screening colonoscopies. In $39.2 \%$ of all colonoscopies, at least one polyp was resected, regardless of histology, with a mean of 0.96 polyp resected per colonoscopy. Of all colonoscopies, $29.8 \%$ had at least one adenoma and for colonoscopies performed in people older than age 50 years, $36.6 \%$ presented at least one resected adenoma. For screening colonoscopies per-
D Table 6 Quality analysis at the level of the department (July to December 2017).

\begin{tabular}{|l|l|}
\hline Quality Indicators (July 2017-December 2017) & \\
\hline Colonoscopies ( $\mathrm{n})$ & 1827 \\
\hline Average BBPS & 7.4 \\
\hline APR (all patients) & $90.7 \%$ \\
\hline APR (outpatients) & $92.2 \%$ \\
\hline APR (inpatients) & $87.2 \%$ \\
\hline CIR (all colonoscopies) & $93.8 \%$ \\
\hline CIR (screening colonoscopies) & $96.5 \%$ \\
\hline PDR & $39.2 \%$ \\
\hline Average number of polyps resected per colonoscopy & 0.96 \\
\hline ADR (all colonoscopies) & $29.8 \%$ \\
\hline ADR 50 & $36.6 \%$ \\
\hline ADR screening & $28.8 \%$ \\
\hline
\end{tabular}

BBPS, Boston Bowel Preparation Score; APR, adequate preparation rate; CIR, cecal intubation rate; $P D R$, polyp detection rate; $A D R$, adenoma detection rate (ADR50, ADR for colonoscopies performed in patients aged 50 years or older; ADR screening, ADR of colonoscopies performed in asymptomatic patients with average risk for CCR).

formed among patients with average risk, the global ADR was $28.8 \%$.

The data table with the list of individual quality scores and scores for the department were shared with the clinicians responsible for the endoscopy unit and the head of the department ( $\triangleright$ Table 5). Individual feedback was provided to each endoscopist, with a comparison between his scores and those for the department and recommended by guidelines ( Table 6). 


\section{Discussion}

The effectiveness of colonoscopy in preventing CRC depends on the quality of the procedure. Several QI have been identified to measure performance of colonoscopy, with the aim of improving its quality. The main outcome of our report was to assess the feasibility and practicality of implementing an automated computer-based quality reporting system for colonoscopy in a tertiary center endoscopy unit, including automatic calculation of ADR.

As previously noted, adequate endoscopic reporting is the cornerstone for quality monitoring, but it is often incomplete and not standardized. The development of electronic reporting system (ERS) helps to fill these gaps by offering predefined and standardized text blocks for procedure details and endoscopic findings and by placing mandatory fields. These ERS also offer a solution for quality monitoring. A first experience was described by van Doorn et al., who developed a completely structured colonoscopy reporting system that generated a standardized and complete report [12]. In the present study, almost all colonoscopies (94\%) were fully reported, including all key QI. In our experience, including a mandatory "quality tab" in the ERS led to an increase in completeness reaching $100 \%$ of procedures in the second part of our implementation. Information for each QI for every colonoscopy performed was prospectively and completely entered.

Of the different QI in the literature, we included three of that have been recognized as key QI: ADR, preparation adequacy, and rate of cecal intubation. ADR is well studied and is the most associated with patient outcomes. It has been inversely associated with risk of interval CRC and CRC-related death [13, $14]$, and its improvement is associated with better outcomes [7]. Adequate preparation allows for good visualization of the mucosa to detect potential lesions, and it promotes complete examination of whole colon, with intubation of the cecum. An incomplete examination leads to inconvenience because the procedure has to be repeated, and to increased costs, and low CIR is associated with increased risk of CCR [3]. Use of these QI underscores some dysfunction. For example, a low CIR may be caused by inadequate preparation can be corrected by modifying the bowel cleansing regimen. Beside these key QI, others are recommended for monitoring, such as the type and rate of adverse events, patient experience, and adherence to post-polypectomy surveillance recommendations [4]. We plan to improve our monitoring system in the future by including these QI.

International societies recommend calculating the ADR among 50-year-old patients with average risk for CCR. We reported all indications, allowing individual ADR interpretation according to endoscopy activity profile. For example, endoscopists with oncological activity (who perform more follow-up colonoscopies) or with therapeutic endoscopy activity both have higher ADRs than a gastroenterologist who follows young patients with inflammatory bowel disease. In this way, we can better interpret results in relationship to the individual profile of each endoscopist.
For ADR calculation, the Dutch experience reports the need for a dedicated research nurse who subsequently reviewed all histopathology results and completed data to the linked endoscopic findings [12]. This double manual entry of data is cumbersome, time-consuming, costly, a source of mistakes. and limits implementation of continued quality recording and assessment [8]. The experience on lower gastrointestinal endoscopy quality monitoring reported by Kim et al. [15] was also based on endoscopy reporting system adaptation. They also reported the need of postponed human intervention to add data on pathological results. To overcome this issue, because data from endoscopy are readily available, PDR was evaluated as an ADR surrogate. The initial studies showed a relatively good correlation between the PDR and the ADR [16-18], but successive studies demonstrated that PDR can be inaccurate in some situations and seems to be a suboptimal QI [19-21]. Beside these reasons, the fact that the PDR calculation is based on manually entered data adds risk from possible human error.

What makes our reported experience original is automatic extraction of both endoscopic and pathological data, which are merged together automatically or on an on-demand basis, through patient identifiers. This system makes possible continuous quality monitoring. It allows automated statistical analyses and quality assessment regularly or on request for our whole endoscopy unit as well as for each endoscopist individually. It also overcomes the problem of double entry of data and related issues.

The system we have described seems reliable because we conducted two manual controls of the automatic extraction of pathology results, and each control showed perfect concordance. Using this analysis, it is possible to evaluate all different QI over any period of time and to provide feedback to unit heads or to individual endoscopists.

\section{Conclusion}

In conclusion, this study illustrates that continuous quality assessment of colonoscopy including automatic ADR extraction is feasible and easily implemented in a Belgian tertiary hospital endoscopy unit with limited human resources by adapting a commercial reporting system and linking it to the pathology department database. Further work must be done to evaluate the potential benefits of automatic computer-based colonoscopy quality recording in terms of unit and individual quality improvement.

\section{Competing interests}

The authors declare that they have no conflict of interest.

\section{References}

[1] Kahi CJ, Imperiale TF, Juliar BE et al. Effect of screening colonoscopy on colorectal cancer incidence and mortality. Clin Gastroenterol Hepatol Off Clin Pract J Am Gastroenterol Assoc 2009; 7: 770-775 
[2] Zauber AG, Winawer S], O'Brien MJ et al. Colonoscopic polypectomy and long-term prevention of colorectal-cancer deaths. N Engl J Med 2012; 366: 687-696

[3] Baxter NN, Sutradhar R, Forbes SS et al. Analysis of administrative data finds endoscopist quality measures associated with postcolonoscopy colorectal cancer. Gastroenterology 2011; 140: 65-72

[4] Kaminski MF, Thomas-Gibson S, Bugajski M et al. Performance measures for lower gastrointestinal endoscopy: a European Society of Gastrointestinal Endoscopy (ESGE) Quality Improvement Initiative. Endoscopy 2017; 49: 378-397

[5] Rex DK, Schoenfeld PS, Cohen J et al. Quality indicators for colonoscopy. Gastrointest Endosc 2015; 1: 31-53

[6] Rees C], Thomas Gibson S, Rutter MD et al. UK key performance indicators and quality assurance standards for colonoscopy. Gut 2016; 65: 1923-1929

[7] Kaminski MF, Wieszczy P, Rupinski M et al. Increased rate of adenoma detection associates with reduced risk of colorectal cancer and death. Gastroenterology 2017; 153: 98-105

[8] Bretthauer M, Aabakken L, Dekker E et al. Requirements and standards facilitating quality improvement for reporting systems in gastrointestinal endoscopy: European Society of Gastrointestinal Endoscopy (ESGE) Position Statement. Endoscopy 2016; 48: 291-294

[9] Anderson JC, Butterly LF. Colonoscopy: quality indicators. Clin Trans। Gastroenterol 2015; 6: e77

[10] Dekker E, Bronzwaer MES. Effective reporting of key performance indicators is essential for balancing the benefits and drawbacks of colonoscopy. Endoscopy 2018; 50: 837-838

[11] Lai EJ, Calderwood AH, Doros G et al. The Boston bowel preparation scale: a valid and reliable instrument for colonoscopy-oriented research. Gastrointest Endosc 2009; 69: 620-625
[12] van Doorn SC, van Vliet J, Fockens P et al. A novel colonoscopy reporting system enabling quality assurance. Endoscopy 2014; 46: 181-187

[13] Kaminski MF, Regula J, Kraszewska E et al. Quality indicators for colonoscopy and the risk of interval cancer. N Engl J Med 2010; 362: 1795-1803

[14] Corley DA, Jensen CD, Marks AR et al. Adenoma detection rate and risk of colorectal cancer and death. N Engl J Med 2014; 370: 12981306

[15] Kim JH, Choi Y], Kwon H] et al. Simple colonoscopy reporting system checking the detection rate of colon polyps. World J Gastroenterol 2015; 21: 9380-9386

[16] Francis DL, Rodriguez-Correa DT, Buchner A et al. Application of a conversion factor to estimate the adenoma detection rate from the polyp detection rate. Gastrointest Endosc 2011; 73: 493-497

[17] Williams JE, Holub JL, Faigel DO. Polypectomy rate is a valid quality measure for colonoscopy: results from a national endoscopy database. Gastrointest Endosc 2012; 75: 576-582

[18] Patel NC, Islam RS, Wu Q et al. Measurement of polypectomy rate by using administrative claims data with validation against the adenoma detection rate. Gastrointest Endosc 2013; 77: 390-394

[19] Boroff ES, Gurudu SR, Hentz JG et al. Polyp and adenoma detection rates in the proximal and distal colon. Am J Gastroenterol 2013; 108 : 993-999

[20] Gohel TD, Burke CA, Lankaala P et al. Polypectomy rate: a surrogate for adenoma detection rate varies by colon segment, gender, and endoscopist. Clin Gastroenterol Hepatol Off Clin Pract J Am Gastroenterol Assoc 2014; 12: 1137-1142

[21] Leung FW. PDR or ADR as a quality indicator for colonoscopy. Am ] Gastroenterol 2013; 108: 1000-1002 